Supplement of Geosci. Model Dev., 13, 1809-1825, 2020

https://doi.org/10.5194/gmd-13-1809-2020-supplement

(C) Author(s) 2020. This work is distributed under

the Creative Commons Attribution 4.0 License.

(c) (1)

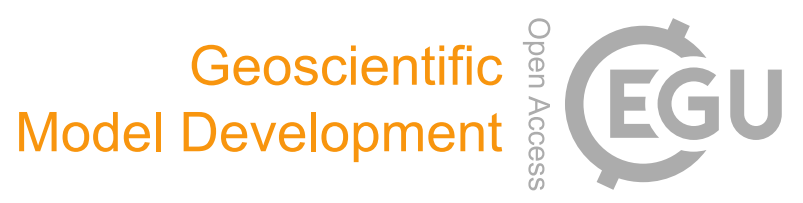

Supplement of

\title{
Verification of the regional atmospheric model CCLM v5.0 with conven- tional data and lidar measurements in Antarctica
}

Rolf Zentek and Günther Heinemann

Correspondence to: Rolf Zentek (zentek@uni-trier.de)

The copyright of individual parts of the supplement might differ from the CC BY 4.0 License. 


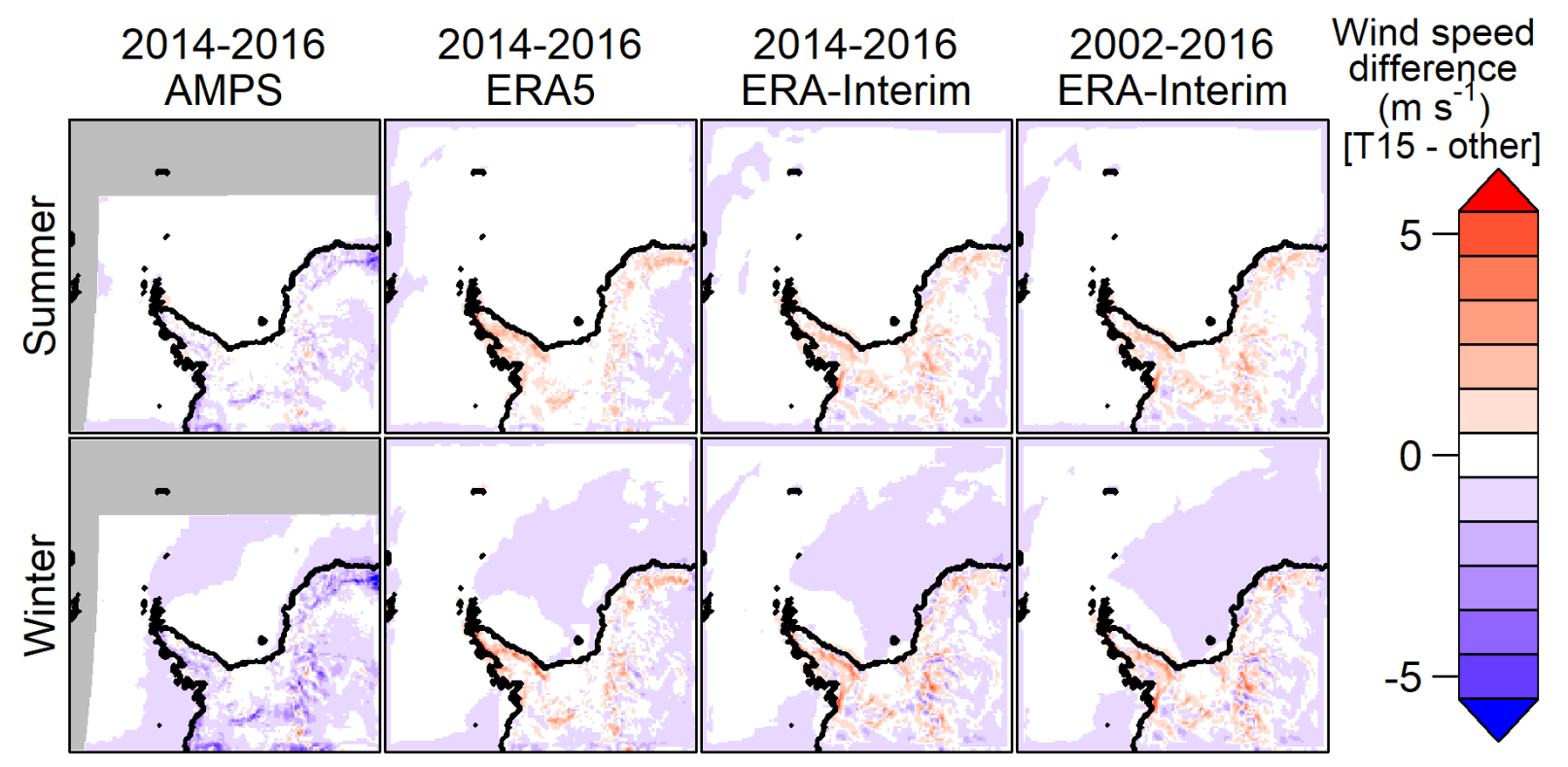

S 1: The $2 \mathrm{~m}$ wind speed difference (T15 minus AMPS, ERA5 and ERA-Interim) for the years 2014-2016 / 2002-2016. Summer (October-March, top) and winter (April-September, bottom) are shown separately. The gray area is outside the AMPS-domain 


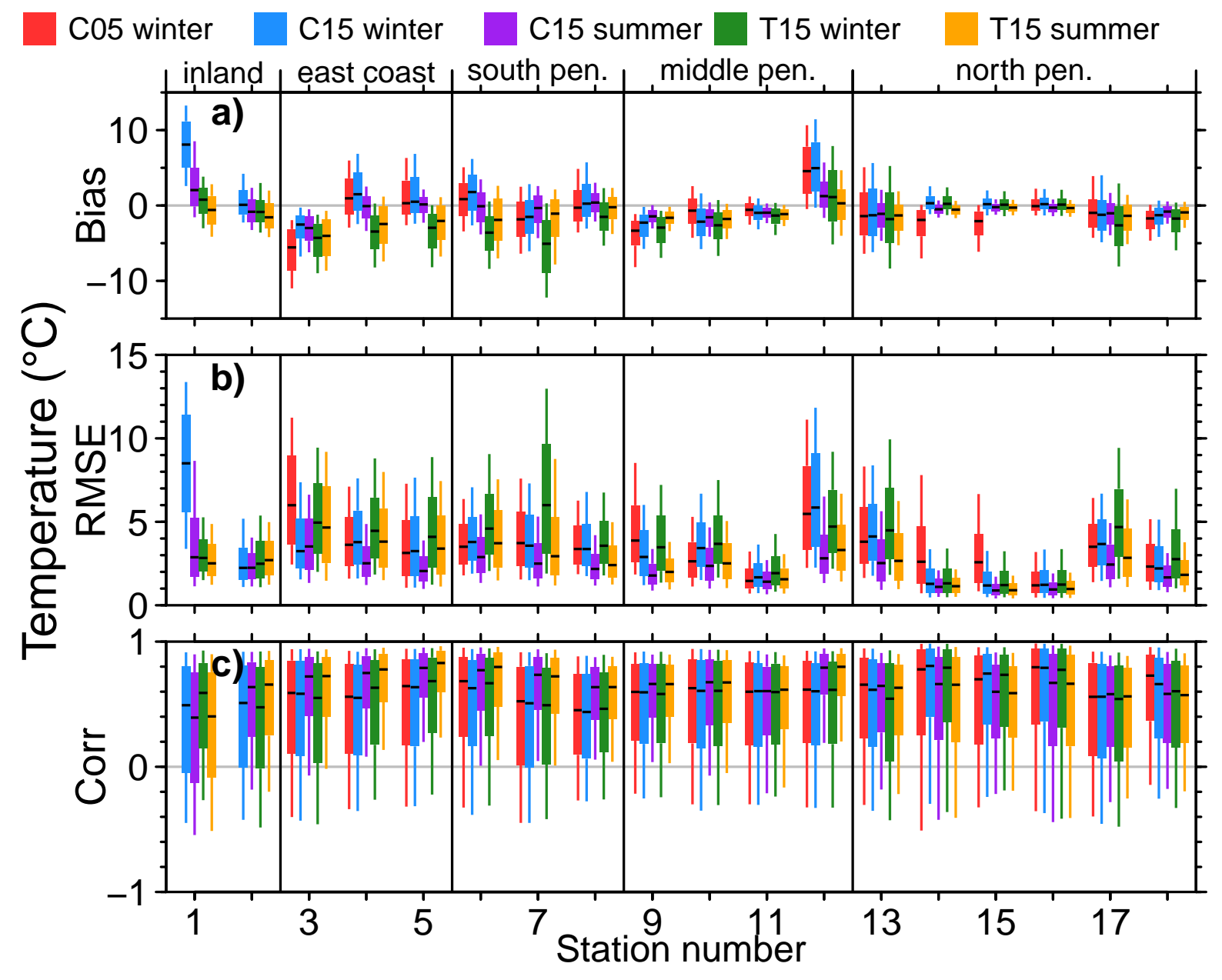

S 2: CCLM (a) $2 \mathrm{~m}$ temperature bias, (b) RMSE and (c) correlation for C05, C15 and T15 for different surface stations. Boxes indicate the $25 / 75 \%$ and whiskers the $10 / 90 \%$ quantile; the median is indicated by a black line inside the box. Statistics (bias, RMSE and correlation) are calculated for every day. 


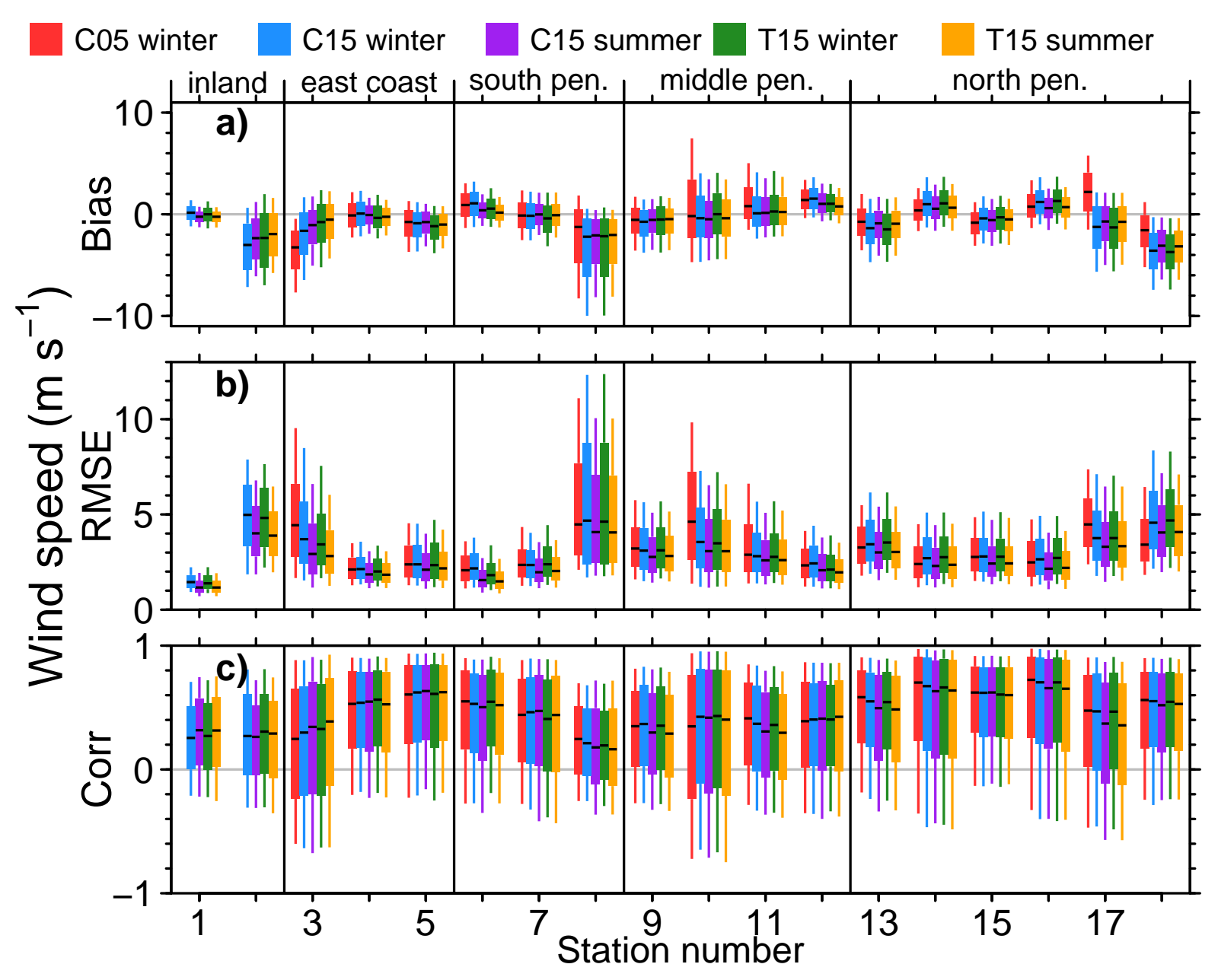

S 3: As Fig. S2 but for $10 \mathrm{~m}$ wind speed. 


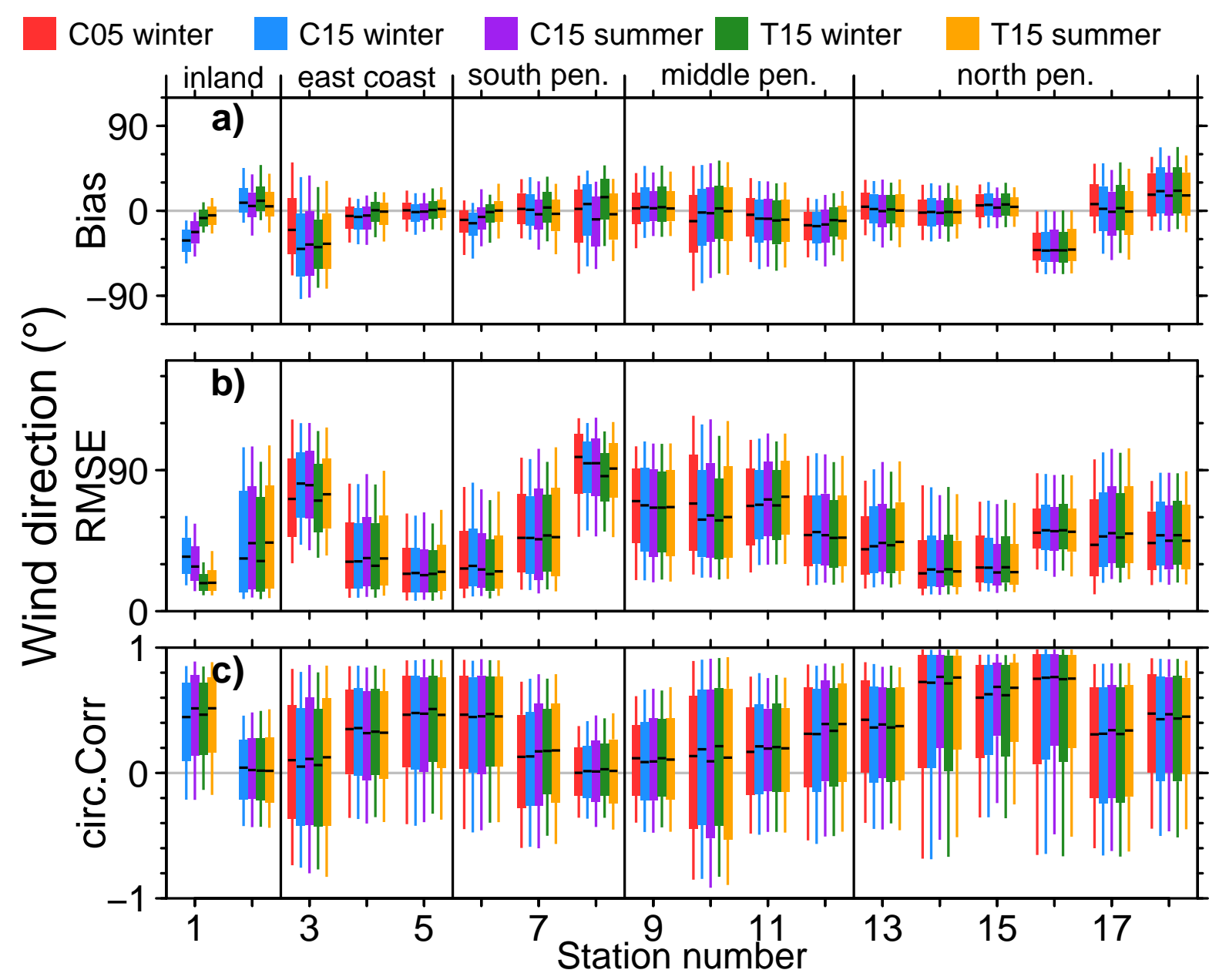

S 4: As Fig. S2 but for $10 \mathrm{~m}$ wind direction. 


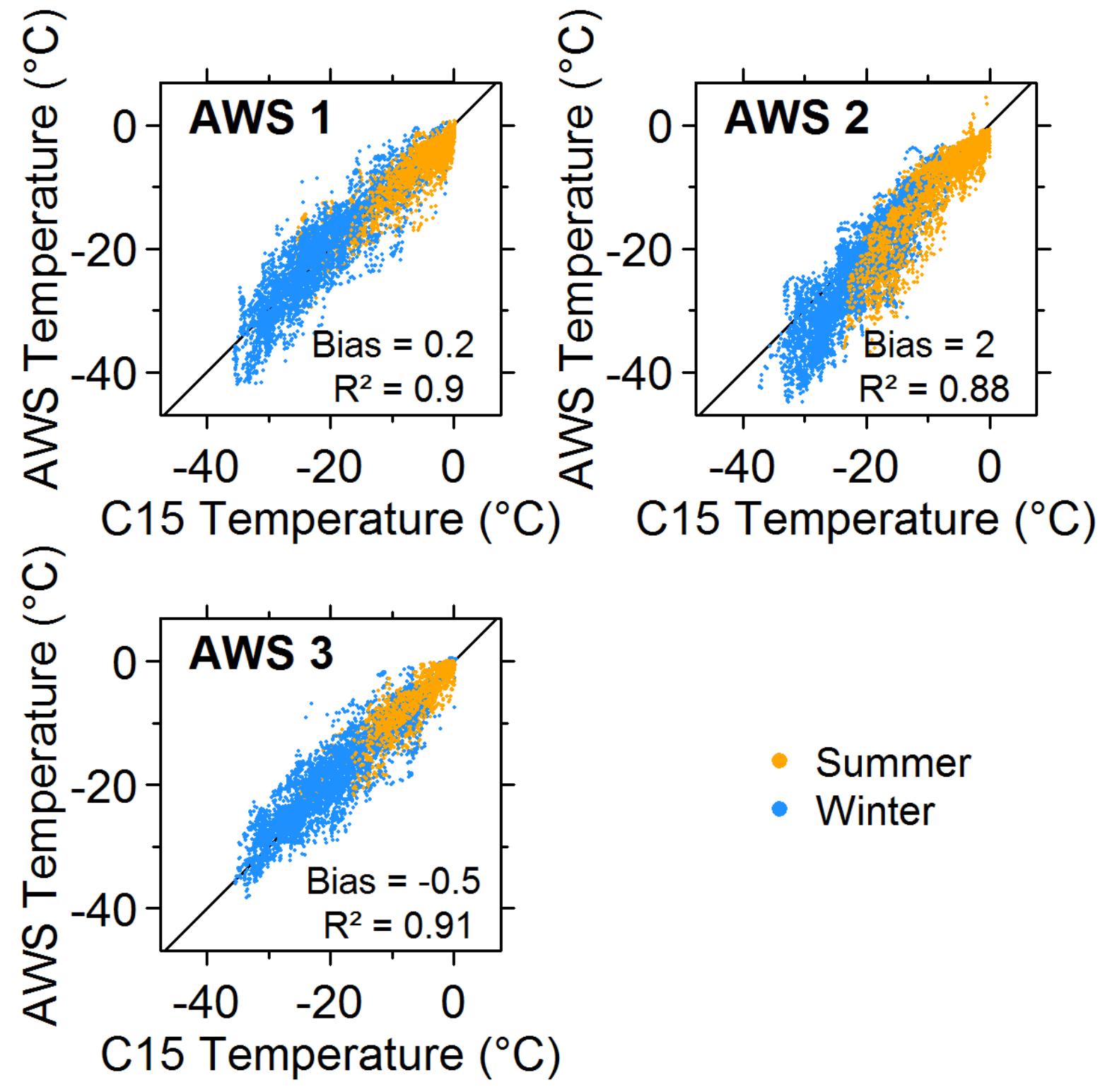

S 5: Temperature of C15 (x-axis) vs Temperature of AWS (y-axis). Values for Summer in orange and for Winter in blue. 


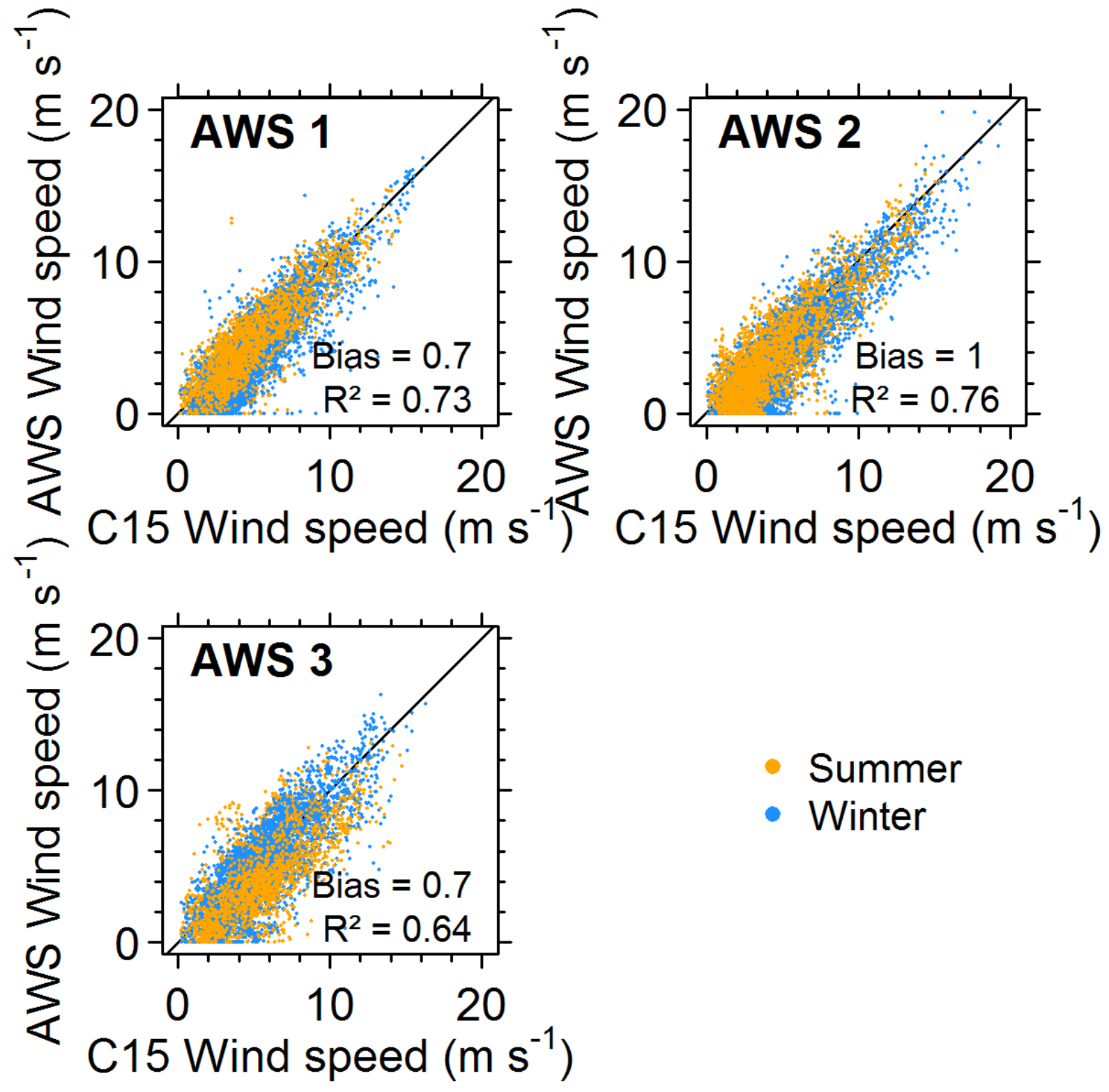

S 6: Like Fig. S5 but for wind speed. 

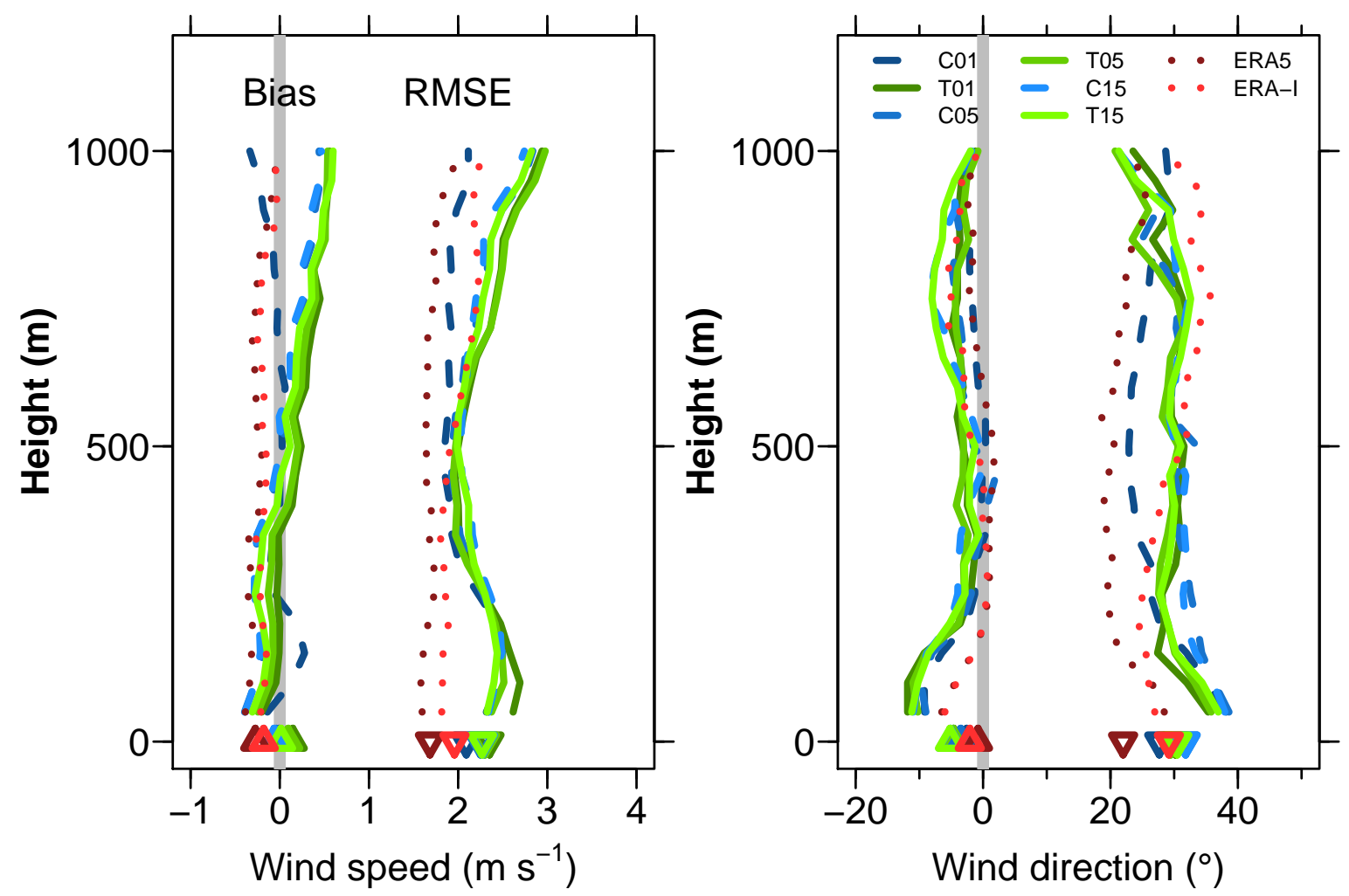

S 7: Bias and RMSE for wind speed (left) and wind direction (right) for CCLM and ERA compared to lidar measurements. Triangles at the bottom indicate the overall bias and RMSE. 

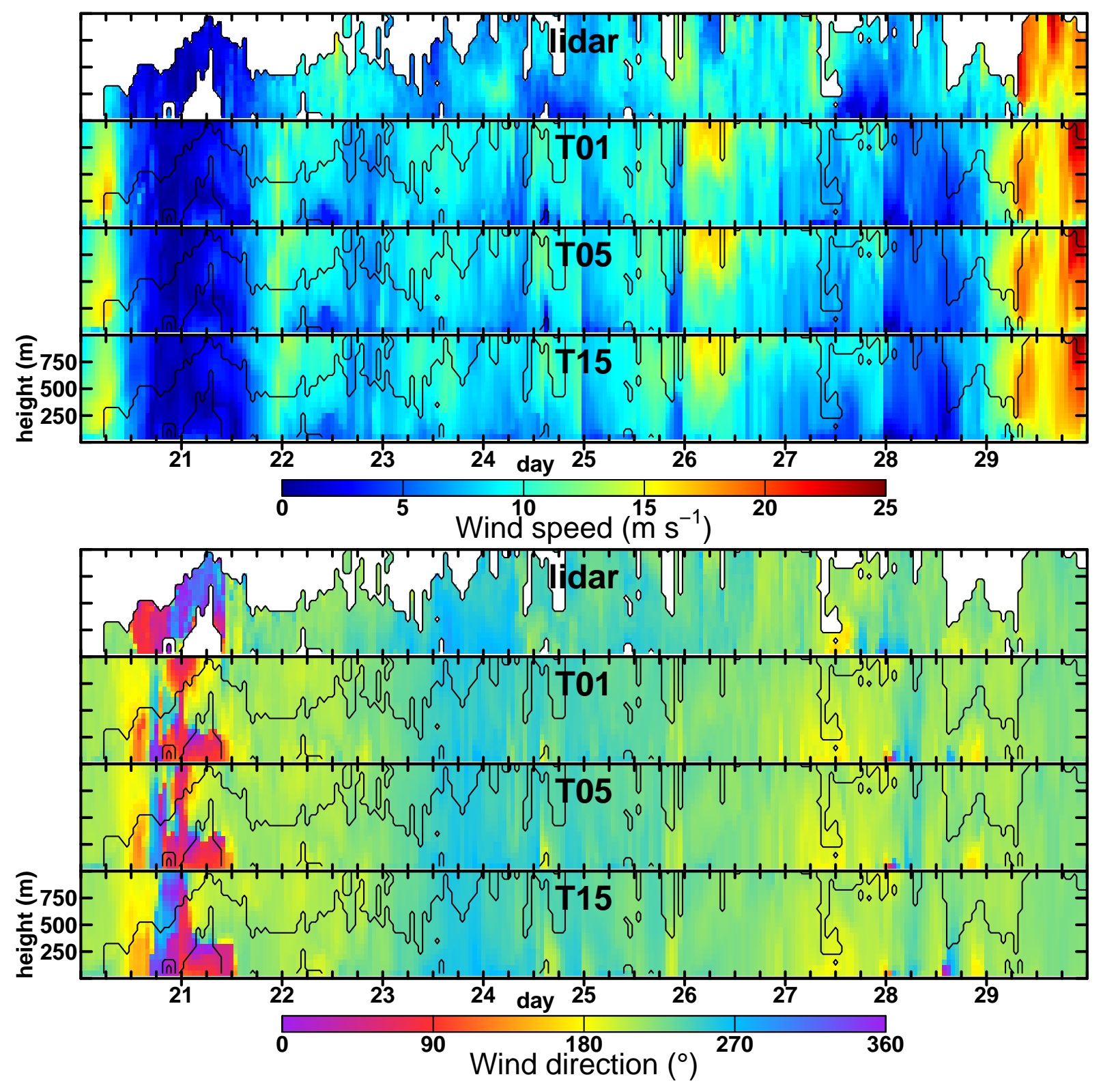

S 8: Time-height cross-sections for wind speed (top) and direction (bottom) for 20 Jan. 00:00 UTC to 30 Jan. 00:00 UTC. 